\title{
Comparison of Analgesic Effect of Perineural Dextrose Injection and Low Level Laser Therapy for Osteoarthritis Knee Pain
}

\author{
IKRAM I. ALYAN, M.D.* and MOHAMED A. EL-ROUBY, M.D.** \\ The Department of Rheumatology \& Rehabilitation, El-Galaa Teaching Hospital* and The Department of Orthopedic Surgery, \\ Faculty of Medicine, Cairo University**
}

\begin{abstract}
Background: Regenerative injection therapy, perineural subcutaneous injection (PSI) of dextrose in low concentration $(5 \%)(\mathrm{D} 5 \mathrm{~W})$ to the subcutaneous nerves and low level laser therapy (LLLT) are analgesic to nerve pain so muscles can restore their normal function. They could be an alternative to conventional symptomatic management of chronic musculoskeletal conditions.
\end{abstract}

Aim of Study: To compare the benefit of PSI with D5W and LLLT on pain modulation in patients suffering from chronic knee osteoarthritis (OA).

Material and Methods: 100 patients aged 40-70 years, either gender with mild to moderate osteoarthritis of knee were studied. They were equally divided into two groups. Group (I) received dextrose injection 5\% in sterile water (D5W) in determined points and group (II) received LLLT. Pain intensity was determined by using visual analogue scale (VAS) and Knee condition was evaluated on the basis of the Western Ontario and McMaster Universities Osteoarthritis Index (WOMAC). The pretreatment and post-treatment outcomes were compared between two groups.

Results: At the end of the treatment, all patients reported improvement in all parameters compared with pretreatment scores. The PSI group injected with D5W showed a significant reduction in pain scale and improved WOMAC scores after end of the treatment compared to LLLT group.

Conclusion: PSI Injection or LLLT could significantly decrease pain in patients with mild to moderate knee osteoarthritis and improve their functional status. PSI was more effective to control pain in our patients.

Key Words: Perineural injection - Low level Laser - Knee osteoarthritis.

\section{Introduction}

PAIN due to knee osteoarthritis (OA) is the most distressing troublesome to patients. The source of pain is not well understood. It is often of multiple origins [1]. Patients are often refractory to usual

Correspondence to: Dr. Ikram I. Alyan, The Department of Rheumatology \& Rehabilitation, El-Galaa Teaching Hospital conventional treatment and different types of intraarticular injection. Researchers usually looking for newer, safe conservative therapy to stop pain [2] Prolotherapy (the term proli is Latin for "to grow"); was introduced as regenerative therapy via injection of solution into or outside the joint space in order to initiate repair and functional restoration of soft tissues in the joint [3]. It was proposed that it had a promising role in diminishing chronic pain of neuropathic and musculoskeletal origin and was associated with immediate pain relieving impact. One of the suggested theories is that neuronal friction may cause chronic constriction injury $(\mathrm{CCI})$ of nerves causing neuropathic pain (4). Perineural subcutaneous injection (PSI) of dextrose in low concentration $(5 \%)$ to superficial CCI which is near to the subcutaneous (under the skin) nerves is analgesic to nerve pain so muscles can restore their normal function [4]. In knee OA, positive outcomes may be achieved by expanding this technique. PSI includes injections around periarticular sensory nerves and particularly their points of fascial penetration, where they pierce the subcutaneous plane [5]. Low-level laser therapy (LLLT) is one of the safe and non-invasive methods which have recently attracted the attention of many researchers and specialists for treatment of knee OA [6]. As regards the protective part of LLLT against synovitis and cartilage degradation in rats [7] and in humans [8]. It was recommended that LLLT may play a double benefit as both an anti-inflammatory impact and a stimulatory impact on tissue repair that make it especially appropriate in osteoarthritis treatment [9].

\section{Objectives:}

In response to the need for alternative safe treatment methods for chronic osteoarthritis, the aim of this study was to compare the efficacy of subcutaneous injection of $5 \%$ dextrose (PSI) to 
LLLT on pain modulation in patients suffering from chronic knee OA.

\section{Material and Methods}

During 2016-2017, one hundred patients aged 40-70 years, either gender with mild to moderate OA [Kellgren-Lawrence (KL) grade I and II] and were dissatisfied with previous attempts at conservative treatment including non-steroidal ant inflammatory drugs were studied. No patient where dropped out. Patients with grade III \& IV OA, malignancy, any knee injection within the last 3 months, body mass index (BMI) $>45 \mathrm{~kg} / \mathrm{m}^{2}$, uncontrolled diabetes mellitus, a recent history of trauma to the knee and any co-morbidity severe enough to prevent participation in the study were excluded. Before the treatment, the pain intensity was determined by using visual analogue scale (VAS), in this scale, 0 indicated no pain and 10 indicated the worst pain. Knee condition was evaluated on the basis of the Western Ontario and McMaster Universities Osteoarthritis Index (WOMAC) which varies between 0 and 96 points and in which lower scores indicate better knee status.

Patients were randomly divided into two equal groups: Group (I) received dextrose injection and group (II) received LLLT. All participants signed the free and informed consent term of the study. Injection Intervention for the group (I): Knee was examined, landmarks were determined. Under sterile condition, a palpation-guided subcutaneous injection of a buffered dextrose $5 \%$ in sterile water (D5W) in determined points was injected using $0.5 \mathrm{~mL}$ of solution with a 25 -gauge needle in 4 points around the knee (Fig. 1) where the periarticular nerves exit the joint capsule. Two points were located at upper lateral and medial parts of the knee joint, one point at a line medial to knee and one point located at the head of the fibula. Additional points were added to patients complain of pain along the saphenous nerve on physical examination. We repeated injection after 1 week and according to participant improvement injection, weekly apart, a total of 4 injections were received. No post-injection analgesics were provided to participants. Treatment was provided for the group (II) included LLLT treatments on 8 points, with a dose of an energy of $6 \mathrm{~J} /$ point for 60 seconds, with a total dose of $48 \mathrm{~J}$ in each session. The selected eight points are the medial and lateral epicondyles of the tibia and femur, the medial and lateral knee joint gap, and the medial edge of the tendon of the biceps femoris and semitendinosus muscles in the popliteal fossa. LLLT therapy was administered 2 times/week for 3 weeks with a low power laser (power $50 \mathrm{~mW}$, continuous wave, wavelength 830 $\mathrm{nm})$. Finally, the pretreatment and post-treatment outcomes were compared between two groups.

\section{Statistics:}

Demographic characteristics are demonstrated as mean \pm standard deviation (continues data). The statistical analyses consisted of chi-square, repeated measure ANOVA, $t$-test, and paired $t$-test; a $p$ value less than 0.05 were considered significant. Statistical analysis was performed by using SPSS statistical difference software ver. 15.0.

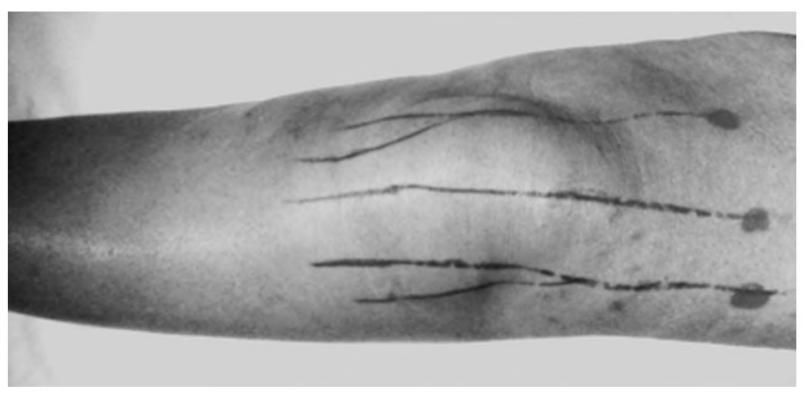

Fig. (1): Points of periarticular injection around the knee.

\section{Results}

In this study, from November 2016 to December 2017, a total of 100 patients were assessed they were randomized in two equal groups. The base line characteristics of patients are presented Table (1), shows that no statistically significant difference between the demographic data between the two groups. Table (2), shows that there was no difference between the 2 groups according to VAS and WOMAC scores before treatment. VAS score shows significant improvement $(p<0.001$ in group I treated with peri-articular injection than group II treated by LLLT at end of the treatment. Also, WOMAC score improved after treatment in both groups. Comparing both groups, patients that were treated with peri-articular injection had significant improvement $p<0.0001$. WOMAC subscales are presented in Table (2).

Table (1): Comparison of Demographic data between the two groups $($ no=100).

\begin{tabular}{llll}
\hline Variable & Group I & Group II & $p$-value \\
\hline Age & $59.2 \pm 12.4$ & $59.4 \pm 15.2$ & 0.349 \\
Sex: Male/Female & $21 / 29$ & $22 / 28$ & 0.492 \\
Body mass index, $\mathrm{Kg} / \mathrm{m}^{2}$ & $31.3 \pm 1.2$ & $31.9 \pm 0.9$ & 0.752 \\
$\begin{array}{l}\text { Duration of pain } \\
\quad \text { (before treatment/month) }\end{array}$ & $7.5 \pm 0.9$ & $8.2 \pm 0.8$ & 0.1 \\
\hline
\end{tabular}


Table (2): Comparison of VAS \& WOMAC subclasses between the two groups.

\begin{tabular}{llllc}
\hline Variables (SD) & Group I & Group II & $\begin{array}{c}p \text {-value } \\
\text { (within groups) }\end{array}$ & $\begin{array}{c}p \text {-value } \\
\text { (between groups) }\end{array}$ \\
\hline VAS: & & & & \\
$\quad$ Before treatment & $7.31 \pm 1.6$ & $7.81 \pm \mathrm{a} 1.71$ & $<0.0001^{* *}$ & 0.15 \\
$\quad$ After treatment & $5.00 \pm 2.27$ & $5.90 \pm 2.68$ & & \\
WOMAC, total score: & & & & 0.77 \\
$\quad$ Before treatment & $46.66 \pm 13.12$ & $45.28 \pm 10.28$ & $<0.0001^{* * * *}$ & \\
$\quad$ After treatment & $36.22 \pm 12.2$ & $38.36 \pm 12.88$ & & 0.69 \\
Pain: & & & & \\
$\quad$ Before treatment & $11.42 \pm 3.94$ & $9.22 \pm 2.2$ & $<0.0001^{* * *}$ & \\
$\quad$ After treatment & $7.52 \pm 4.25$ & $9.56 \pm 5.36$ & & 0.7 \\
Stiffness: & & & & \\
$\quad$ Before treatment & $2.33 \pm 1.02$ & $3.56 \pm 1.8$ & $<0.0001^{* * *}$ & \\
$\quad$ After treatment & $1.84 \pm 0.94$ & $3.78 \pm 1.73$ & & 0.89 \\
Function: & & & & \\
$\quad$ Before treatment & $34.55 \pm 9.1$ & $33.6 \pm 5.85$ & $<0.0001^{* * *}$ & \\
$\quad$ After treatment & $26.44 \pm 9.29$ & $26.78 \pm 8.43$ & & \\
\hline
\end{tabular}

VAS: Visual Analogue Scale (0-10).

WOMAC: Western Ontario McMaster University Osteoarthritis Index (0-96).

SD : Standard deviation.

\section{Discussion}

Both perineural subcutaneous injection (PSI) and LLLT are emerging harmless approaches which can be effectively utilized in mild to moderate knee OA [10]. PSI is an injection of buffered dextrose $5 \%(\mathrm{D} 5 \mathrm{~W})$ solution close to subcutaneous peripheral nerves in order to quick relieve of pain such as knee OA to restore its normal function [11] Usual injection sites in knee OA were at superficial $\mathrm{CCI}$ of the anterior femoral cutaneous nerve of the thigh, obturator nerve, and saphenous nerve [11] A new review described the efficacy of dextrose prolotherapy than injection of local anesthesia and exercise program [12]. A comparative study in 2017, presented a prominent decrease in WOMAC scores in peri- articular injection than intra-articular forms [5]. A practically identical outcome was recorded in the previous report in 2013, in which dextrose injection accomplished a significant change in the WOMAC composite score [13].

LLLT is a type of photo-biomodulation therapy in which low-frequency continuous laser of typically 540 hundred-830nm wavelengths [10], utilized for stimulation of the process of healing and diminishing of pain. Previous studies using LLLT has shown its effectiveness in dealing with Achilles tendonitis [14], cervical pain [15], lumbar pain and newly on agonizing mild to moderate osteoarthritis knee joint [6].

In response to the requirement for more up to date, safe, alternative modalities of management for chronic pain associated with knee osteoarthritis, given the current drugs with side effects, we seek to compare the use of PSI prolotherapy and LLLT benefits.

Our results showed that both PSI and LLLT can be effectively used as rapid management of pain associated with knee OA. The improvement in all patients we reported reflected by VAS and WOMAC scores, further, our patients in PSI group showed a statistically significant and clinically relevant impact on the pain scale and improvement of total WOMAC and subclasses scores at end of the study compared with LLLT group. Our results demonstrated that the improvement in WOMAC scores is consistent with the previous study [11] of knee OA using PSI. We compared the effect of PSI to LLLT, both had pain modulation effect. In the present study, we did not recommend the use posttreatment analgesic drugs to observe the improvement of patients with the management.

A superior impact of peri-articular prolotherapy on the WOMAC score and diminishing of knee disability compared with intra-articular injections was recorded [11], also pain score was significantly lower at 5-month visits in the peri-articular group they studied compared with the intra-articular group [11]. In 2007 Lyftogt, utilized similar idea and treated joint pain and swelling in OA by inhibiting neurogenic inflammation using dextrose prolotherapy [16]. The peri-articular injection was recommended to be a simple technique, effective and safe. Applying it could avoid some problems could occur with intra-articular injection [11] particularly in some compromised patients. 
Comparing application of active LLLT 2/week continuous wave and a dose of $6 \mathrm{~J} / \mathrm{cm}^{2}$ over 4 weeks to placebo LLLT [17], it was found that patients treated with the active diode laser demonstrated significant improvements in pain, and knee flexion compared with the control sham group. Franico et al., [18] reported limitation of the clinical trials available involving both LLLT and prolotherapy injections used adjunctively. Our patients treated with LLLT showed significant improvement in pain and WOMAC scores, but it was less significant compared to group I treated with PSI. No one of our patients studied showed side effects. Dextrose is inexpensive and safe complementary treatment to decrease pain. Taking into consideration that intra-articular injections have serious complications such as septic arthritis, PSI could be a substitute.

\section{Conclusion:}

PSI Injection or LLLT could significantly decrease pain in patients with mild to moderate knee osteoarthritis and improve their functional status. PSI was more effective to control pain in our patients.

\section{Recommendations:}

Although neural Prolotherapy is an effective novel and evolving treatment for non-malignant persistent pain, based on sound neuroscientific principles, it may be a short time and pain will recur to prevent this problem for patients, we recommended body posture and daily activities correction, isometric quadriceps setting exercise, healthy dieting and weight control and lifestyle modification. Additional studies are required to detect the precise mechanism of PSI on pain modulation.

\section{References}

1- LITWIC A., EDWARDS M.H., DENNISON E.M. and COOPER C.: Epidemiology and burden of osteoarthritis. Br. Med. Bull., 105: 185-199, 2013.

2- HAUSER R.A., LACKNER J.B., STEILEN-MATIAS D. and HARRIS DK.: A systematic review of dextrose prolotherapy for chronic musculoskeletal pain. Clin. Med. Insights Arthritis Musculoskeletal. Disord, 9: 139-59, 2016.

3- RABAGO D., MUNDT M., ZGIERSKA A. and GRETTIE J.: Hypertonic dextrose injection (prolotherapy) for knee osteoarthritis: Long term outcomes. Complement Ther. Med., 23 (3): 388-95, 2015.

4- WALDMAN S.D., editor. Pain Management. ${ }^{2 n d}$ ed. Philadelphia: Saunders, 2011.

5- Hamid Reza Farpour and Farzane Fereydooni: Comparative effectiveness of intra-articular prolotherapy versus peri-articular prolotherapy on pain reduction and improving function in patients with knee osteoarthritis: A rand- omized clinical trial. Electron Physician. Nov., 9 (11): 5663-5669, 2017.

6- YOUSEfi-NOORAIE R., SCHONSTEIN E., HEIDARI K., et al.: Low level laser therapy for nonspecific lowback pain. Cochrane Database Syst Rev., 16 (2): Cd005107.doi: 10.1002/14651858, 2008.

7- OLIVEIRA P., SANTOS A.A. and RODRIGUES T. Effects of phototherapy on cartilage structure and inflammatory markers in an experimental model of osteoarthritis. J. Biomed Opt., 18: 128004, 2013.

8- NAMBI G.S., KAMAL W. and GEORGE J.: Radiological and biochemical effects (CTX-II, MMP-3, 8, and 13) of low-level laser therapy (LLLT) in chronic osteoarthritis in Al-Kharj, Saudi Arabia. Lasers Med. Sci., 32: 297-303, 2016.

9- ALFREDO P.P., BJORDAL M.J., DREYER H.S., et al.: Efficacy of low level laser therapy associated with exercises in knee osteoarthritis: A randomized double-blind study. Clin. Rehabil., 26: 523, 2012.

10- VINICIUS TIEPPO FRANCIO, ROBERT S. DIMA, CHRIS TOWERY and SAEID DAVANI: Prolotherapy and Low Level Laser Therapy: A Synergistic Approach to Pain Management in Chronic Osteoarthritis. Oct., 17: (5) Anesth. Pain Med., 2017.

11- ZAHRA REZASOLTANI, MEHRDAD TAHERI, MORTEZA KAZEMPOUR MOFRAD and SEYED AMIR MOHAJERANI: Periarticular dextrose prolotherapy instead of intra-articular injection for pain and functional improvement in knee osteoarthritis. J. Pain Res., 10: 1179-1187, 2017.

12- CHEN-YU HUNG, MING-YEN HSIAO, KE-VIN CHANG, DER-SHENG HAN and TYNG-GUEY WANG: Comparative effectiveness of dextrose prolotherapy versus control injections and exercise in the management of osteoarthritis pain: A systematic review and meta-analysis. J. Pain Res., 9: 847-857, 2016.

13-RABAGO D., PATTERSON J., MUNDT M., KIJOWSKI R., GRETTIE J., SEGAL N.A. and ZGIERSKA A.: Dextrose prolotherapy for knee osteoarthritis: A randomized controlled trial. Ann. May-Jun., 11 (3): 229-37, 2013.

14- BJORDAL J.M., LOPES-MARTINS R.A. and IVERSEN V.V.: A randomized, placebo controlled trial of low level laser therapy for activated Achilles tendinitis with microanalysis measurement of peritendinous prostaglandin E2 concentrations. Br. J. Sports Med., 40 (1): 76-80, 2006.

15- GUR A., SARAC A.J., CEVIK R., ALTINDAG O. and SARAC S.: Efficacy of $904 \mathrm{~nm}$ gallium arsenide low level laser therapy in the management of chronic myofascial pain in the neck: A double-blind and randomize-controlled trial. Lasers Surg. Med., 35 (3): 229-35, 2004.

16- LYFTOGT J.: Subcutaneous prolotherapy treatment of refractory knee, shoulder and lateral elbow pain. Australasia Musculoskeletal. Med., 12 (2): 110-112, 2007.

17- HEGEDUS B., VIHAROS L., GERVAIN M. and GALFI M.: The effect of low-level laser in knee osteoarthritis: a double blind, randomized, placebo-controlled trial. Photomed Laser Surg., 27 (4): 577-584, 2009.

18- TIEPPO FRANCIO V., DIMA R.S., TOWERY C. and DAVANI S.: Prolotherapy and Low Level Laser Therapy: A Synergistic Approach to Pain Management in Chronic Osteoarthritis, Anesth. Pain Med., 7 (5), 2017. 


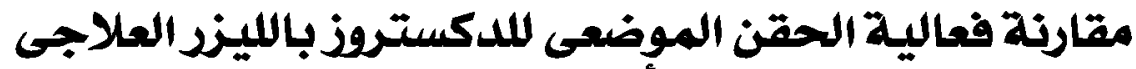

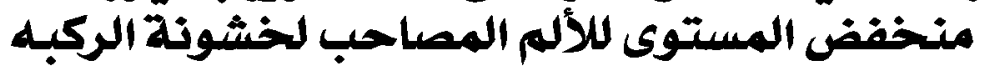

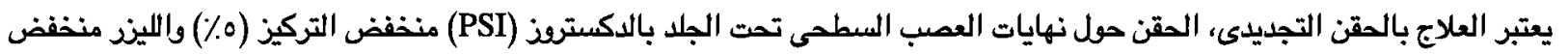

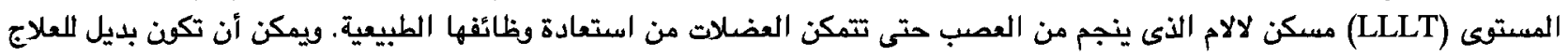
التحفظى النمطى اللحالات المزمنة للجهاز الهيكى والجمن العضلى.

الهدف: مقارنة الفائدة بكل من العلاج بحقن نهايات العصب السطحى والليز العلاجى منخفض المستوى لحالات ألم الركبة المزمن

المصاحب الخشونة.

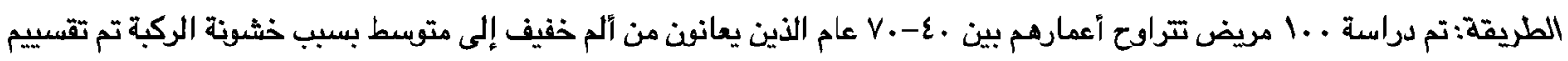

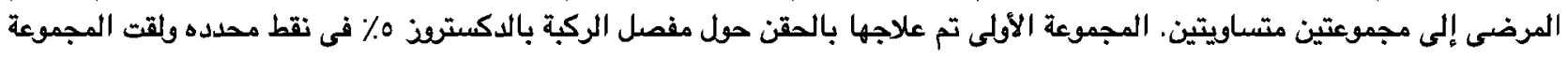

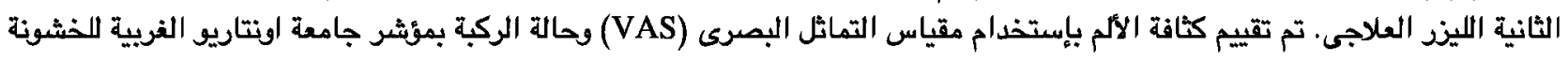
وتمت مقارنة نتائج المعالجة المبدئية وما بعد نهاية العلاج.

النتأج: وجد تحسن ملحوظ لجميع العناصر مثل تحسن درجة الالام ومعدلات الخشونة للمجموعتين ولكن فى المجموعة الأولى التى ثلقت الحقن كان تحسن المعيار الإحصائى.

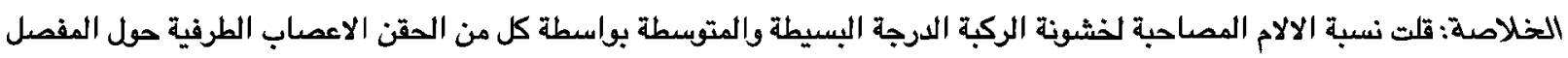

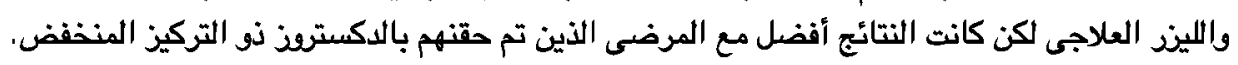

